1 Edlund E, Johnsson U, Lidgren L, et al. Palmoplantar pustulosis and sternocostoclavicular arthro-osteitis. Ann Rheum Dis 1988; 47: 809-15.

2 Fallet G H, Arroyo J, Vischer T L. Sternocostoclavicular hyperostosis. Case report with a 31 year followup. Arthritis Rheum 1983; 26: 784-90.

3 Sonozaki H, Mitsui H, Miyanaga $\mathrm{Y}$, et al. Clinical features of 53 cases with pustulotic arthro-osteitis. Ann Rheum Dis 1981; 40: 547-53.

4 Gerster J C, Lagier R, Nicod L. Sternocostoclavicular hyperostosis (SCCH). Skeletal Radiol 1985; 14: 53-60.

5 Sartory D J, Schreiman J S, Kerr E, Resnik C S, Resnick D. Sternocostoclavicular hyperostosis: a review and report of 11 cases. Radiology 1986; 158: 125-8.

6 Chamot A M, Benhamou C L, Kahn M F, Beranek L, Kaplan G, Prost A. Le syndrome acné pustulose hyperostose ostéite (SAPHO). Résultats d'une enquête nationale. 85 observations. Rev Rhum Mal Osteoartic 1987; 54: 187-96.

7 Karagevrekis Ch, Fallet G H, Lagier R. Spinal changes in association with sternocostoclavicular changes in association with sternoco

8 Lagier R, Arroyo J, Fallet G H. Sternocostoclavicular hyperostosis. Radiological and pathological study of a specimen with ununited clavicular fracture. Pathol Res Pract 1986; 181: 596-603.

Cricothyroid arthritis in a child with familial Mediterranean fever

Sir: We describe for the first time the occurrence of cricothyroid arthritis in a girl who first presented with migratory polyarticular arthritis but eventually developed the classical features of familial Mediterranean fever.

A 9 year old Palestinian Arab girl was admitted in January 1979 with fever and migratory polyarticular arthritis of the large joints. The heart was normal. The erythrocyte sedimentation rate was $110 \mathrm{~mm} / \mathrm{h}$ and the antistreptolysin $\mathrm{O}$ titre was $\mathbf{4 0 0}$ Todd units. A diagnosis of acute rheumatic fever was made and treatment was started with secondary prophylaxis. During the following six years she had several episodes of arthritis, which were interpreted as recurrence of acute rheumatic fever due to irregular prophylaxis, and occasional fever and abdominal pain.

In January 1985 the girl was admitted with fever and arthritis of both elbows and the right wrist. Next morning she developed arthritis of the cricothyroid joint. The diagnosis was verified by indirect laryngoscopy. She also developed arthritis of the interphalangeal joints of both hands. She became better after five days of aspirin treatment. Two months later she had another similar episode of transient arthritis of the cricothyroid and interphalangeal joints. During the following three years the girl had several episodes of fever and abdominal pain, with the frequency progressively increasing to one to two attacks a week. She also developed arthritis of the ankles associated with erysipelas-like erythema Family history disclosed that her mother, maternal aunt, and two sisters had had similar recurrent episodes. Prophylaxis with colchicine was effective in decreasing the frequency of febrile and painful episodes; during the past 12 months the girl has had only three mild abdominal attacks and one episode of transient arthritis of the left ankle.

The synovial attack of familial Mediterranean fever typically appears as acute monoarthritis affecting a large joint of the lower extremity. ${ }^{1-4}$ Involvement of the small joints, including the temporomandibular, sternoclavicular, and metatarsophalangeal joints, has been described in a minority of patients with familial Mediterranean fever, ${ }^{1-4}$ whereas involvement of the interphalangeal joints has been reported to be most unusual. ${ }^{\prime}$ Cricothyroid arthritis in the course of familial Mediterranean fever has not been previously described.

The presentation with migratory polyarticular arthritis, the involvement of the interphalangeal joints, and the long period before the appearance of the classical manifestations of familial Mediterranean fever are other unusual features in this case.

$$
\begin{array}{r}
\text { FAISAL A KHUFFASH } \\
\text { HASSAN A MAJEED } \\
\text { Department of Paediatrics } \\
\text { Faculty of Medicine } \\
\text { Kurwait University } \\
\text { PO Box } 24923
\end{array}
$$

13110 Safat, Kuwait

1 Heller H, Gafni J, Michaeli D, et al. The arthritis of familial Mediterranean fever (FMF). Arthriti Rheum 1966; 9: 1-17

2 Majeed H A, Barakat M. Familial Mediterranean fever (recurrent hereditary polyserositis) in children: analysis of 88 cases. Eur $\mathcal{f}$ Pediat 1989; 148: 636-41.

3 Sneh E, Pras M, Michaeli D, Shahin N, Gafni J. Protracted arthritis in familial Mediterranean fever. Rheumatology and Rehabilitation 1977; 16: 102-6.

4 Simon G, Marbach J J. Familial Mediterranean fever with temporomandibular joint involvement. Pediatrics 1976; 57: 810-2.

\section{Trauma and seronegative} spondyloarthropathy

Sir: We would like to offer what we believe to be a necessary reply to Professor Panayi's letter published in the Annals. 'Professor Panayi considers that in the two B27 positive patients we described, who developed peripheral arthritis immediately after trauma, physical injury and the onset of peripheral arthritis were only coincidental. The first case represents, in his opinion, a reactive arthritis following gastroenteritis, and the second case arthritis of the knees begun by chance after the trauma.

If other articles on this subject ${ }^{3-6}$ are not taken into account this may seem to be the most logical conclusion, partly because no evidence of causality may be produced other than the immediate onset of peripheral arthritis after trauma, and the lack of an infective trigger. Wisnieski ${ }^{3}$ and Masson et $a l^{4}$ have reported other cases of peripheral arthritis in B27 positive subjects immediately after physical injury. In some of these, like our patient $1,{ }^{2}$ there was also urethritis with negative urethral smears and culture, in addition to arthritis. Our patient also had a diarrhoea with negative stool culture, which subsided in two days without any treatment. In 1982 Jacobs et al reported that five of their 58 patients with juvenile onset B27 positive spondyloarthropathy had a trauma severe enough for a doctor to be consulted before the onset of peripheral arthritis. ${ }^{5}$ In 1988 we reported the cases of two B27 positive subjects who had never had pain to peripheral joints before, but developed an erosive peripheral arthritis of the right hip shortly after a severe physical injury to the same joint. ${ }^{6}$ The rapid evolution of the destructive process, which is not usual in erosive arthritis of seronegative spondyloarthropathy, provides further evidence in favour of the triggering role of trauma.

In conclusion, the articles published on the subject suggest that as in psoriatic arthropathy, ${ }^{78}$ physical injury may, in B27 positive subjects, trigger the onset of a peripheral arthritis predominantly affecting the injured joints. We hope that others will report similar cases and perform studies on the synovial fluid and blood of patients with B27 associated peripheral arthritis following trauma, in an attempt to understand the pathogenetic mechanisms. We appreciate the comments of Professor Panayi and thank him for drawing attention to this topic of seronegative spondyloarthropathy.

IGNAZIO OLIVIERI GABRIELE GEMIGNANI GIAMPIERO PASERO Rheumatic Disease Unit Institute of Medical Pathology 1 University of Pisa Pisa, Italy

${ }^{*}$ Correspondence to: Dr Ignazio Olivieri, Istituto di Patologia Medica 1, Servizio di Reumatologia, Via Roma 67, 56100 Pisa, Italy.

1 Panayi G S. Trauma and seronegative spondyloarthropathy. Ann Rheum Dis 1989; 48: 879.

2 Olivieri I, Gemignani G, Christou C, Pasero G. Trauma and seronegative spondyloarthropathy: report of two more cases of peripheral arthritis precipitated by physical injury. Ann Rheum $D$ i 1989; 48: 520-1.

3 Wisnieski J J. Trauma and Reiter's syndrome: development of 'reactive arthropathy' in two patients following musculoskeletal injury. Ann Rheum Dis 1984; 43: 829-32.

4 Masson G, Thomas P, Bontoux D, Alcalay M. Influence of trauma on initiation of Reiter's syndrome and ankylosing spondylitis. Ann Rheum Dis 1985; 44: 860-1.

5 Jacobs J C, Berdon W E, Johnston A D. HLA B27-associated spondyloarthritis and enthesopathy in childhood: clinical, pathologic, and radiographic observations in 58 patients. $\mathcal{J}$ Pediatr 1982; 100: 521-8.

6 Olivieri I, Gherardi S, Bini C, Trippi D, Ciompi M L, Pasero G. Trauma and seronegative spondyloarthropathy: rapid joint destruction in peripheral arthritis triggered by physical injury. Ann Rhewm Dis 1988; 47: 73-6.

7 Williams K A, Scott J T. Influence of trauma on the development of chronic inflammatory polyarthritis. Ann Rheum Dis 1967; 26: 532-7.

8 Wright V. Psoriatic arthritis. In: Scott J T, ed. Copeman's textbook of the rheumatic diseases. 6th ed. Edinburgh, London, Melbourne, New York: Churchill Livingstone, 1986: 775-86.

Chondroprotective drugs and osteoarthritis

Sir: I read with interest the leader article by Doherty on 'Chondroprotection by nonsteroidal anti-inflammatory drugs' published in the Annals.'

Although I am in general agreement with the views expressed by Dr Doherty, he raised some issues which I consider deserve further comment.

In his article Dr Doherty questions the relevance of certain laboratory derived data on non-steroidal anti-inflammatory drugs (NSAIDs) to their clinical use in osteoarthritis. He considers the standard for assessing these drugs is the long term symptomatic and functional improvement in patients 'rather than individual biochemical or structural characteristics'. It should be noted, however, that most NSAIDs are also powerful analgesics and may effectively relieve the symptoms of osteoarthritis without necessarily influencing its progression. Pain relief and improvement of joint mobility are thus inadequate criteria for distinguishing between an NSAID acting only as an analgesic and an NSAID which is also positively influencing the underlying osteoarthritic disease. More objective methods of clinical assessment of patient response to drug treatment are therefore required before this matter can be resolved. Such methods are presently under investigation, and promising findings have been reported with biochemical markers of cartilage breakdown in synovia fluid $^{2-4}$ and serum, ${ }^{56} x$ ray microfocal (Buckland-Wright et al, unpublished data) 